\title{
SISTEM PAKAR MENDIAGNOSA KEMUSYRIKAN UMAT ISLAM DENGAN METODE FORWARD CHAINING
}

\author{
Charles Bronson Harahap ${ }^{1}$, Wirhan Fahrozi ${ }^{1}$, Evta Indra ${ }^{2}$ \\ ${ }^{1}$ Universitas Potensi Utama Fakultas Teknologi dan Ilmu Komputer \\ ${ }^{2}$ Universitas Prima Indonesia Fakultas Teknologi dan Ilmu Komputer \\ JL. KL. Yos Sudarso Km. 6,5 No. 3-A, Tanjung Mulia · Medan \\ E-mail : wirhanfr@gmail.com
}

\begin{abstract}
ABSTRAK- Syirik dalam arti mempersekutukan Tuhan dengan menjadikan sesuatu, sebagai obyek pemujaan, dan tempat menggantungkan harapan dan dambaan. Perbuatan ini mengingkari kemahakuasaan dan kemahasempurnaan-Nya. Syirik adalah pangkal segala kejahatan dan penyelewengan serta rusaknya pikiran atau tingkah laku. Dengan kemajuan teknologi informasi maka dimungkinkan informasi mengenai kemusyrikan umat islam ini dapat diimplementasikan kedalam bentuk sebuah sistem informasi yang akurat mengenai diagnosa kemusyrikan umat islam. Dalam hal ini diperlukan analisa yang tepat untuk mempercepat proses identifikasi. Oleh karena itu perlu menggunakan aplikasi sistem pakar yaitu aplikasi komputer yang berprilaku layaknya seorang ahli. Sistem pakar mampu memecahkan masalah yang biasanya hanya dapat dipecahkan oleh seorang pakar dengan menggunakan basis pengetahuan, fakta dan teknik penalaran. Dalam analisa ini menggunakan metode Forward Chaining sebagai mesin inferensi. Dalam pendekatan ini dimulai dari informasi masukan dan selanjutnya menggambarkan kesimpulan. Hasil penelitian ini berupa membangun sistem pakar untuk mendiagnosa kemusyrikan umat islam berbasis web agar nantinya dapat diakses secara daring.
\end{abstract}

Kata kunci : Umat Islam, Syirik, Forward Chaining, Web.

\section{PENDAHULUAN}

Seiring dengan berkembangnya teknologi informasi mendorong setiap orang untuk mampu membuat sebuah sistem yang dapat membantu semua orang apakah itu dalam bentuk pekerjaan, hiburan, dakwah, media pembelajaran dan pengobatan. Hal inilah yang mendorong para ahli untuk berlomba-lomba membuat sistem yang mampu mempermudah pekerjaan manusia.

Permasalahan seputar syirik penting untuk dibahas, karena ia menyangkut dengan keimanan seseorang yang sangat erat kaitannya dalam kehidupan manusia, dan sekaligus merupakan faktor pendorong dalam upaya membina jati diri seorang muslim yang beriman kepada Allah SWT. Umat Islam masih banyak melakukan perbuatan yang menyimpang dari ajaran tauhid yang disebabkan kekurangan mereka terhadap pengetahuan tentang menyekutukan Allah SWT.

Sistem pakar merupakan sistem yang merepresentasikan pengetahuan manusia yang ahli dalam bidang tertentu ke komputer yang dirancang untuk membantu menyelesaikan masalah layaknya seorang pakar. Dengan adanya sistem pakar ini diharapkan orang awam mampu menyelesaikan masalahnya sendiri khususnya mengenai masalah syirik kepada Allah SWT atau sekedar hanya mencari informasi tanpa harus bertemu dengan seorang yang ahli atau ulama. Dalam analisa ini menggunakan metode Forward Chaining sebagai mesin inferensi. Dalam pendekatan ini dimulai dari informasi masukan dan selanjutnya menggambarkan kesimpulan. Hasil penelitian ini berupa membangun sistem pakar untuk mendiagnosa kemusyrikan umat islam berbasis web agar nantinya dapat diakses secara daring

\section{ISI PENELITIAN}

Komponen-komponen pada arsitektur Sistem Pakar saling berhubungan dalam melakukan proses untuk memberikan informasi. Adapun komponenkomponen dari Sistem Pakar untuk menentukan kemusyrikan umat islam adalah sebagai berikut:

1. Basis Data (Database)

2. Basis Pengetahuan (Knowledge Base)

3. Mesin Inferensi (Inference Engine)

4. Antarmuka Pemakai (User Interface)

5. Fasilitas Penjelasan (Explanation Facilitites).

\subsection{Mesin Inferensi}

Mesin inference merupakan otak dari Sistem Pakar, berupa perangkat lunak yang melakukan tugas inferensi penalaran Sistem Pakar, biasanya dikatakan sebagai mesin pemikir. Pada prinipnya mesin inilah yang akan mencari solusi dari suatu permasalahan. Konsep yang biasanya digunakan untuk mesin inferensi adalah runut maju (Forward Chaining), yaitu proses yang bermula dari kondisi yang diketahi menuju tujuan yang diinginkan. Pada Sistem Pakar untuk menentukan kemusyrikan umat islam adalah tampak ketika proses penelusuran dimulai user diminta untuk memilih kriteria-kriteria umat islam yang akan ditampilakan sistem. Selanjutnya sistem melakukan penelusuran pada rule untuk mencari fakta berdasarkan kriteria-kriteria syirik dalam menentukan kemusyrikan umat islam, apabila ditemukan sesuai aturan maka proses 
dilanjutkan menarik kesimpulan kemusyrikan umat islam.

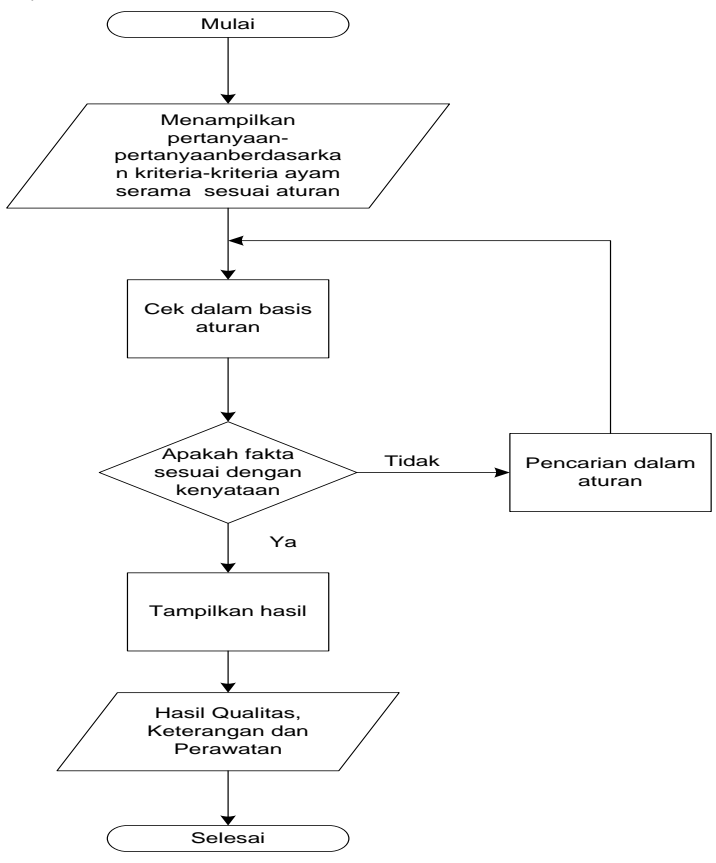

Gambar 1. Flow Chart Mesin Inferensi

\subsection{Basis Data}

Perancangan database pada Sistem Pakar dalam mendiagnosa kemusyrikan umat islam ini bertujuan untuk memberikan gambaran data yang akan dibutuhkan. Untuk databasenya terdiri dari 5 tabel, yaitu: tabel admin, tabel Gejala, tabel syirik, tabel relasi, dan tabel konsultasi.

\subsection{Basis Pengetahuan}

Data pada mesin inferensi yang telah diinput pemakai akan diproses dengan penalaran Forward Chaining. Mesin inferensi Forward Chaining digunakan dalam sistem ini untuk mengindentifikasi kemusyrikan umat islam setelah menerima kriteriakriteria kemusrikan yang diinput oleh user. Setelah proses input data kriteria selesai, maka sistem akan memberikan beberapa pertanyaan berkaitan dengan kriteria yang dirasakan oleh user tersebut. Dalam menjawab setiap pertanyaan, sistem telah menyediakan pilihan jawaban yang akan digunakan oleh user yang telah ditentukan pada sistem. Setiap jawaban yang diberikan oleh user akan dicari kesesuaian dengan kriteria suatu kemusyrikan tertentu yang ada dalam knowledge-based. Untuk mendukung penalaran menentukan diagnose kemusyrikan umat islam berdasarkan kriteriakriteria yang ada. Basis pengetahuan mengandung pengetahuan untuk pemahaman dan penyelesaian masalah yang dapat berasal dari pakar, jurnal dan sumber pengetahuan lain. Adapun pengetahuan yang berasal dari pakar, jurnal maupun sumber pengetahuan lain tersebut adalah kemusyrikan umat islam dan kriteria-kriteria yang dimilikinya. Dalam penelitian ini penulis menggunakan beberapa data kriteria yang dapat sejalan dengan kemusyrikan umat islam.

\subsection{Basis Data Antarmuka Pemakai}

Untuk memudahkan pengoperasian sistem ini, maka rancangan antar muka dibagi atas beberapa jenis, yang disesuaikan dengan fungsinya masingmasing yaitu:

1. Form Login Administrator/User

Form ini merupakan tampilan awal program yang sekaligus berfungsi sebagai pengamanan sistem, karena pada form ini hak akses pemakai dibedakan antara, pemakai tingkat admin dan pemakai tingkat user. Tampilan dari form login adminisrator seperti pada gambar di bawah ini

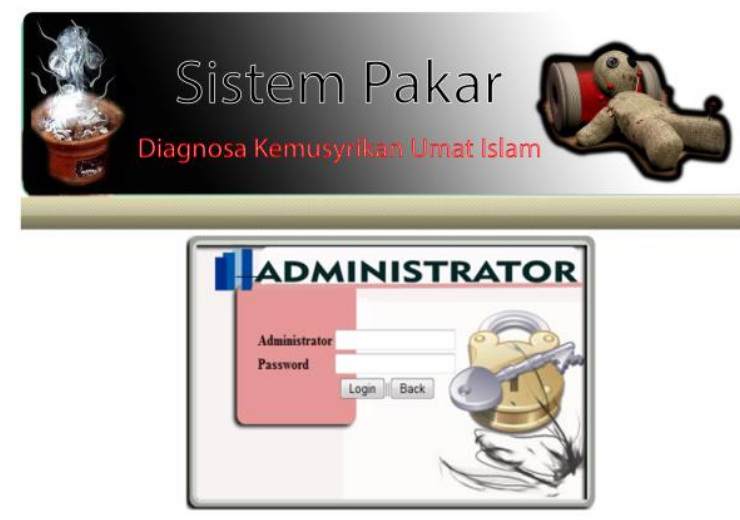

Gambar 2. Tampilan Login Administrator

\section{Form Data Kriteria}

Form data kriteria adalah kumpulan dari kriteriakriteria yang mengacu pada kemusyrikan umat islam. Form data kriteria memiliki field kode_kriteria dan nama kriteria. Dalam form ini hanya admin yang memiliki hak akses atas penambahan kriteria, edit kriteria dan hapus kriteria.

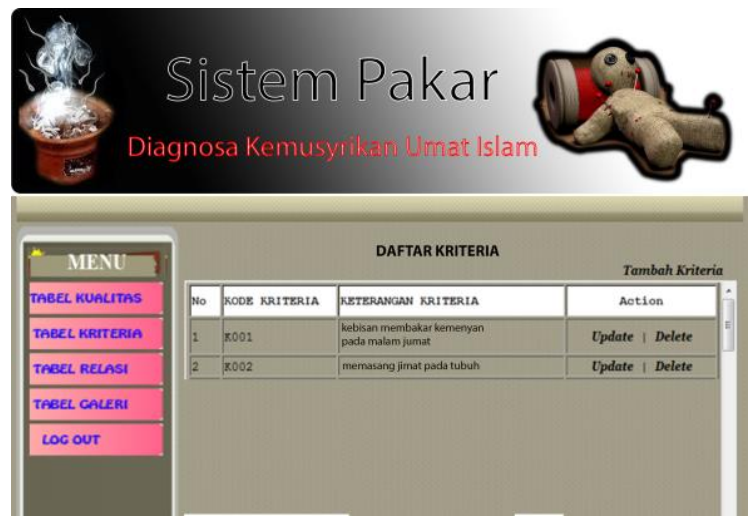

Gambar 2. Tampilan Data Kriteria

\section{Form Data Kemusyrikan}

Form data kemusyrikan adalah kumpulan dari kemusyrikan umat islam. Form data kemusyrikan berisikan field kode_kemusyrikan, nama kemusyrikan, keterangan dan solusi umat islam. Dalam form ini hanya admin yang memiliki hak 
akses atas penambahan kemusyrikan, edit kemusyrikan dan hapus kemusyrikan dapat dilihat pada gambar 5.4.

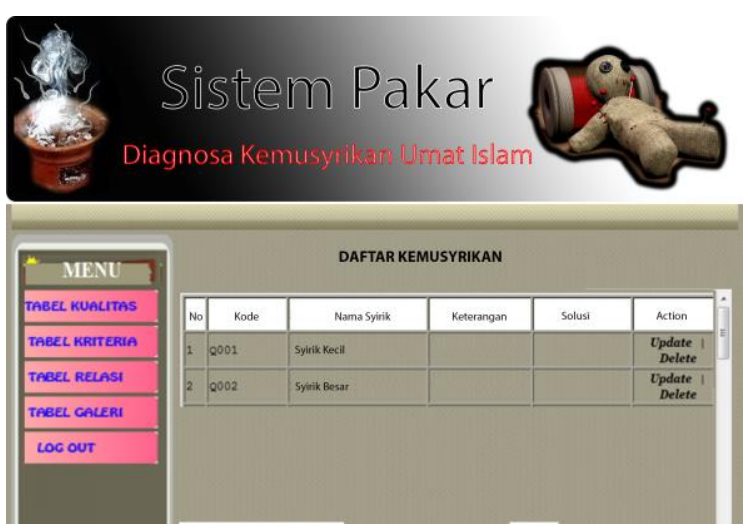

Gambar 2. Tampilan Data Kemusyrikan

\section{Form Data Rule}

Form data rule adalah berisikan rule-rule untuk mengidentifikasi kemusyrikan umat islam di mana pada form ini relasi antara kriteria dan kemusyrikan yaitu untuk membuat pertanyaan kepada user berdasarkan kriteria dan menemukan kemusyrikan umat islam. Dalam form ini berisikan kode rule, kode kriteria, pilihan "ya". Apabila dipilih "ya" selanjutnya akan bisa lanjut ke kriteria selanjutnya atau sudah menemukan kemusyrikan, begitu selanjutnya untuk pilihan "tidak". Dalam form ini hanya dapat diakses oleh admin untuk tambah rule, edit dan hapus.

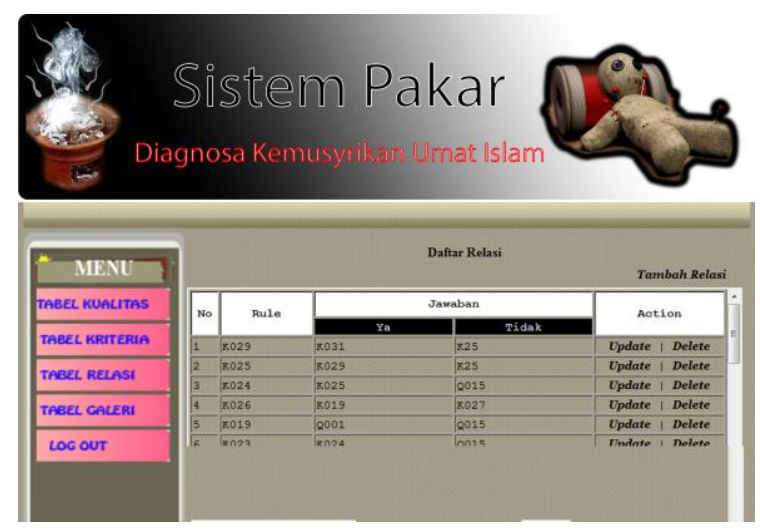

Gambar 2. Tampilan Data Rule

5. Form Konsultasi Kemusyrikan Umat islam

Setelah user selesai membuat akun dan login, kemudian user akan memilih menu konsultasi. Di mana pada menu ini akan ditampilkan pertanyaanpertanyaan kepada user berdasarkan rule yang sudah ditentukan. Pertanyaan berupa kriteria-kriteria umat islam dan user harus menjawab pertanyaan yang disediakan sistem. Kemudian user akan mendapatkan hasil dari jawaban tersebut berupa kemusyrikan umat islam berdasarkan kriteriakriteria yang dipilih. Pada form konsultasi kemusyrikan umat islam ini pertanyaan berupa "Ya" dan "Tidak"

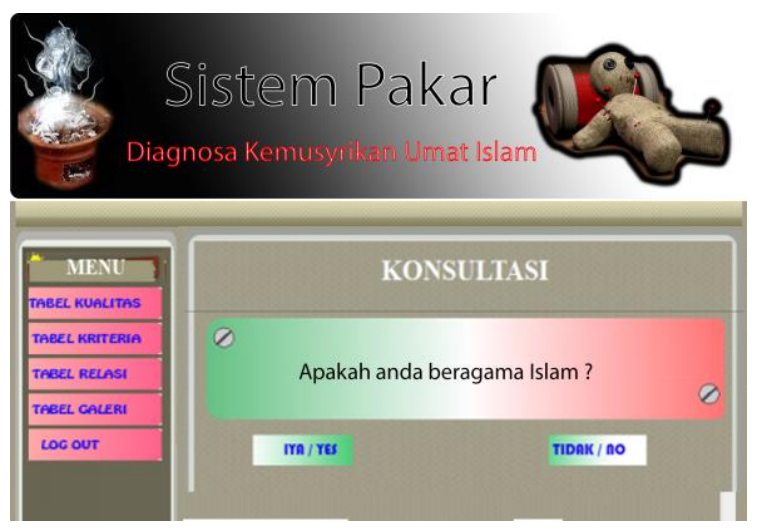

Gambar 2. Tampilan Form Konsultasi

\section{Form Hasil Konsultasi}

Pada form hasil dari konsultasi kemusyrikan adalah menampilkan kemusyrikan yang dimiliki oleh umat islam beserta solusinya.

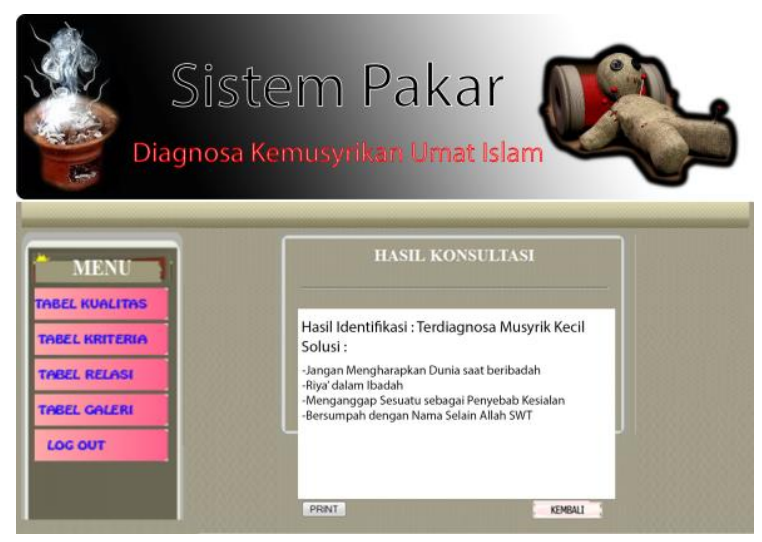

Gambar 2. Tampilan Hasil Konsultasi

\section{KESIMPULAN}

Berdasarkan penelitian dan pembahasan yang dilakukan, maka dapat disimpulkan beberapa hal sebagai berikut :

1. Aplikasi Sistem Pakar yang dirancang dapat memberikan informasi mengenai kemusyrikan umat islam dari data kriteria umat islam yang dimasukkan.

2. Kecepatan dalam mengindentifikasi dalam Sistem Pakar tergantung pada banyak rule yaitu data kemusyrikan umat islam dan kriteria-kriteria umat islam yang dimasukkan, semakin banyak rule yang dimasukkan maka tingkat akurasi dan ketepatan hasil identifikasi semakin tepat. 
3. Metode Forward Chaining bisa digunakan untuk melakukan penelusuran untuk mendapatkan hasil kemusyrikann umat islam.

\section{UCAPAN TERIMAKASIH}

Penulis mengucapkan terimakasih yang sebesarbesarnya kepada DRPM Ditjen Penguatan Risbang dan pihak-pihak yang membantu pelaksanaan penelitian dalam memberikan kesempatan berupa sumbangsih dana, dan informasi kepada peneliti pada skema peneltian dosen pemula pada kasus mendiagnosa kemusyrikan umat islam.

\section{DAFTAR PUSTAKA}

[1]Hamka, Tafsir Al-Azhar, (Jakarta : Pustaka Panjimas, 1982).

[2] Muhammad 'Imaduddin 'Abdulrahim, Kuliah Tauhid, (Jakarta : GemaInsani Press, 2002).

[3]Muhammad bin Ibrahim bin Abdullah AtTuwaijiri, Ensiklopedi Islam al-Kamil, (Jakarta : Darus Sunnah, 2013).

[4]Yusuf Qardhawi, Hakikat Tauhid dan Fenomena Kemusyrikan, Terj.Musyaffa, (Jakarta : Robbani Press, 2005).

[5]Erianto Ongko (2013), "PERANCANGAN SISTEM PAKAR DIAGNOSA PENYAKIT PADA MATA", Prosiding Seminar Nasional Informastika.

[6]Muhammad Fauzi (2013), "SISTEM PAKAR MENDETEKSI KERUSAKAN SOUND EFFECT PADA GITAR ELEKTRIK", Prosiding Seminar Nasional Informastika.

[7]Rangkuti A Haris dan Andryana Septi (2009), "Deteksi Kerusakan Notebook Dengan Menggunakan Metode Sistem Pakar", ISSN 1978-9491.

[8]D. Sitanggang et al., "Application of forwardchaining method to diagnosis of onion plant diseases," in Journal of Physics: Conference Series, 2018, vol. 1007, no. 1.

[9] O. Sihombing, E. Indra, S. M. F. Situmeang, and R. E. Suraya, "PENERAPAN METODE CERTAINTY FACTOR PADA APLIKASI SISTEM PAKAR DIAGNOSA PENYAKIT PARU BERBASIS WEB," SNITIK (Prosiding Semin. Nas. Inov. Teknol. dan Ilmu Komput., 2018.) 